\title{
Consumo alimentar e ecologia de populações ribeirinhas em dois ecossistemas
} amazônicos: um estudo comparativo ${ }^{1}$

\section{Food intake and ecology of riverine populations in two Amazonian ecosystems: a comparative analysis}

\author{
Rui Sérgio Sereni MURRIETA² \\ $M$ aissa Salah BAKRI ${ }^{2}$ \\ Cristina ADAMS 3 \\ Perpétuo Socorro de Souza OLIVEIRA ${ }^{4}$ \\ Roberto STRUMPF²
}

\section{RE S U M O}

\section{Objetivo}

Este artigo analisa e compara os dados de consumo alimentar de duas populações ribeirinhas da Amazônia vivendo em ecossistemas contrastantes de floresta tropical: a várzea estacional e a floresta de terra firme.

\section{Métodos}

Foi estudado o consumo alimentar de 11 unidades domésticas na várzea (Ilha de Ituqui, M unicípio de Santarém) e 17 na terra firme (Floresta Nacional de Caxiuanã, Municípios de M elgaço e Portel). 0 método utilizado foi 0 recordatório de 24 horas. As análises estatísticas foram executadas com o auxílio do programa Statistical Package for Social Sciences 12.0 .

\section{Resultados}

Em ambos os ecossistemas, os resultados confirmam a centralidade do pescado e da mandioca na dieta local. Porém, a contribuição de outros itens alimentares secundários, tais como o açaí (em Caxiuanã) e o leite in natura (em Ituqui), também foi significante. Além disso, o açúcar revelou ser uma fonte de energia confiável para enfrentar as flutuações sazonais dos recursos naturais. Parece haver ainda uma maior contribuição

\footnotetext{
1 Esta pesquisa foi real izada com financiamento do Ministério da Ciência e Tecnologia, Ministério do Desenvolvimento Social e Combate à Fome e Conselho Nacional de Desenvolvimento Científico e Tecnológico, a partir do Edital MCT/MESA/CNPq/ CT-Agronegócio 01/2003 (processo CNPq no 502943/2003-3), da Fundação de Amparo à Pesquisa do Estado de São Paulo (processo 96-7487/2) e do Instituto de Pesquisa Ambiental da Amazônia.

2 Universidade de São Paulo, Instituto de Biociências, Departamento de Genética e Biologia Evolutiva, Laboratório de Estudos Evolutivos Humanos. R. do Matão, Travessa 14, n. 321, sala 242, Cidade Universitária, Zona Leste, 05508-900, São Paulo, SP, Brasil. Correspondência para/Correspondence to: R.S.S. MURRIETA. E-mail: <murrietabr@yahoo.com.br>.

3 Universidade de São Paulo, Escola de Artes, Ciências e H umanidades, Laboratório de Ecologia H umana. São Paulo, SP, Brasil.

4 Pesquisadora autônoma. Santarém, PA, Brasil.
} 
energética dos peixes para a dieta de Ituqui, provavelmente em função da maior produtividade dos rios e lagos da várzea em relação à terra firme. Por fim, Ituqui revelou uma maior dependência de itens alimentares comprados, enquanto Caxiuanã mostrou estar ainda bastante vinculada à agricultura e às redes locais de troca.

\section{Conclusão}

Além dos resultados confirmarem a importância do pescado e da mandioca, também mostraram que produtos industrializados, como o açúcar, têm um papel importante nas dietas, podendo apontar para tendências no consumo alimentar relacionadas com a atual transição nutricional e com a erosão, em diferentes níveis, dos sistemas de subsistência locais.

Termos de indexação: Antropologia nutricional. Consumo alimentar. Ecossistemas amazônicos. Mandioca. Peixes.

\section{A B S T R A C T}

\section{Objective}

This article analyses and compares data on household food intake of two Amazonian riverine populations settled in different rain forest ecosystems: terra firme (land not subject to annual flooding) forest and floodplain.

\section{Methods}

Food surveys were carried out in 11 households at the floodplain area (Ituqui Island), located in the Municipality of Santarém, and in 17 households at the terra firme area (Caxiuanã National Forest), located in the Municipalities of M elgaço and Portel. Household food consumption data were collected using the 24-hour food recall method. Data analysis was run in Statistical Package for Social Sciences, version 12.0.

\section{Results}

The results confirm, in both ecosystems, the central roles of fish and manioc in the local diet. Nevertheless, other secondary food items, e.g. açai (in Caxiuanã) and milk (in Ituqui) are also important. In addition, sugar stands out as a reliable household energy source to cope with the extreme seasonality of rain forest natural resources. In addition, there seems to be a greater caloric contribution of fish in Ituqui's diet, probably due to the higher productivity of lakes and rivers in Ituqui varzea (low and flat land alongside a watercourse). Finally, Ituqui has shown greater dependency over purchased items, whereas Caxiuanã has still a strong reliance on agricultural activities and on local social and economic exchange networks.

\section{Conclusion}

Besides confirming the importance of fish and manioc, results have also shown that industrialized products, such as sugar, play an important role in local diets, and may point towards new tendencies in food consumption related to the current nutritional transition and to the erosion of local subsistence systems.

Indexing terms: Nutritional anthropology. Food consumption. Amazonia ecosystem. Manihot. Fishes.

\section{N T R O D U Ç Ã O}

É consenso que os padrões alimentares de sociedades tradicionais em todo o globo vêm sofrendo uma série de mudanças, caracterizadas, principalmente, pela substituição gradual de produtos locais por importados e pelo aumento do consumo de gorduras e carboidratos simples ${ }^{1-3}$. No Brasil, esse novo panorama nutricional, associado a algumas políticas nacionais, vem contribuindo para a diminuição na prevalência da desnutrição infantil, ao mesmo tempo em que vem favorecendo o crescimento do excesso de peso e da obesidade, especialmente entre adolescentes ${ }^{4}$. Esse processo tem sido particularmente intenso e complexo no País devido às profundas diferenças entre classes sociais e contextos regionais socioeconômicos ${ }^{5}$.

Apesar de terem começado há, pelo menos, três décadas, foi só nos últimos 15 anos que as mudanças nos padrões alimentares da população brasileira têm sido estudadas apropriada- 
mente $^{5}$. Mesmo assim, a atenção da maioria desses estudos está voltada para populações urbanas do Sul, Sudeste e Nordeste. As populações rurais brasileiras foram, pelo menos até recentemente, negligenciadas. Na Amazônia, este quadro é ainda mais precário, já que o segmento populacional menos estudado é exatamente o mais expressivo, os caboclos ou ribeirinhos. Somado a isto, são poucas as pesquisas sobre dieta que abordem os padrões alimentares como reflexo de mudanças socioeconômicas e ecológicas mais profundas ${ }^{6}$ e que lidem concomitantemente com a natureza multicausal e biocultural da alimentação humana 7,8 .

Frente aos aspectos acima discutidos, este artigo tem como objetivos principais caracterizar, identificar e comparar os padrões de consumo alimentar doméstico de duas populações caboclas assentadas em diferentes ecossistemas amazônicos de floresta tropical. Dessa forma, pretende-se contribuir para o esboço de um perfil de padrões e variações regionais da alimentação de populações ribeirinhas da Amazônia, e sua relação com fatores ecológicos e socioeconômicos locais ${ }^{9-15}$.

\section{Sociedades caboclas amazônicas}

As populações Caboclas, ou ribeirinhas, da Amazônia são produto da miscigenação entre índios e colonizadores portugueses e, posteriormente, escravos africanos trazidos para a região ${ }^{16}$. A té os anos 1970, foi pouco o interesse acadêmico por estas sociedades ${ }^{17}$. Nesse período, os problemas econômicos e ecológicos enfrentados pelos novos imigrantes, provenientes, na sua maioria, do Nordeste e do Sul do País, atraídos pelos grandes projetos de desenvolvimento, em contraste com o que acontecia às populações campesinas nativas (os caboclos), despertaram a atenção de pesquisadores de várias disciplinas para as últimas. Desde então, o número de pesquisas sobre este segmento da população vem crescendo significativamente, principalmente na última década. Estes estudos têm evidenciado um perfil regional caracterizado por sistemas de subsistência dominados pela pesca, caça, agricultura de corte e queima, extração e comercialização de produtos florestais e engajamento crescente em atividades assalariadas ${ }^{11}$.

Das espécies cultivadas, a mandioca (Manihot esculenta Crantz) é o recurso vegetal mais importante, constituindo a principal fonte de energia na dieta dessas populações ${ }^{11,14,18}$. Além dos derivados da mandioca, as populações caboclas demonstram uma grande dependência em relação ao pescado ${ }^{12}$. Apresentam, ainda, uma multiplicidade de itens alimentares secundários altamente sazonais e uma crescente dependência de produtos de mercado, principalmente os industrializados provenientes de outras regiões do País ${ }^{12,18,19}$. Esta tendência parece vir acompanhada, na maioria dos casos, pelo abandono de práticas de subsistência tradicionais e perda total ou parcial da auto-suficiência na produção de alimentos ${ }^{20}$.

Além disso, os poucos estudos sobre padrões nutricionais de populações caboclas apresentam um perfil marcado pelas idiossincrasias do meio ambiente amazônico: níveis moderados de desnutrição crônica ${ }^{10,12,21,22 ;}$; baixa absorção de micronutrientes devido às altas taxas de infestação parasitária e à pouca variedade de itens alimentares, $12,13,21$; e consumo protéico elevado em relação ao energético, com ligeira insuficiência em termos energéticos ${ }^{10,12,14,15,18}$.

\section{M É TO D O S}

\section{A llha de Ituqui}

A llha de Ituqui localiza-se na calha principal do Rio Amazonas, no Baixo Amazonas, $30 \mathrm{~km}$ a jusante da cidade de Santarém (PA), e possui uma área de 21 mil hectares. A ilha é coberta por um mosaico de vegetação florestal secundária e savanas altamente adaptadas ao ciclo de inundação sazonal. Durante o inverno (estação chuvosa), que se estende de dezembro a junho, a maior parte da ilha fica submersa. 0 verão (estação seca) ocorre de agosto a início de dezembro ${ }^{23}$. 
Os solos das várzeas são normalmente considerados ricos e férteis, principalmente em comparação aos da terra firme adjacente; aptos, portanto, a uma produção agrícola considerável. No entanto, a sazonalidade extrema do ambiente de várzea tem implicações diretas para o potencial de uso do solo, limitando os tipos de planta que podem ser cultivados ${ }^{23}$.

De acordo com o levantamento sócioeconômico realizado por Câmara \& McGrath ${ }^{24}$, no início da década de 90 , a população total da ilha de Ituqui era de cerca de 2 mil habitantes. Em um levantamento censitário, realizado em setembro de 1997, as comunidades estudadas por esta pesquisa, São Benedito e Aracampina, contabilizaram 240 moradores na primeira, divididos em 36 unidades domésticas (média de 6,7 moradores/unidade doméstica), e 380 habitantes na segunda, divididos em 60 casas, com uma média de 6,3 pessoas por domicílio ${ }^{14}$ (Tabela 1).

Os principais cultivares nas duas comunidades são a mandioca, o milho (usado principalmente para a alimentação da criação doméstica de aves), o feijão e as cucurbitáceas. A pesca é realizada no rio (no canal do Ituqui ou na calha principal do Amazonas) e nos lagos interiores ${ }^{11,25}$, sendo mais intensa no verão. A criação de gado em São Benedito e Aracampina tem papel importante na economia da ilha, apesar do impacto das inundações anuais sobre esta atividade. Durante a cheia, o rebanho tem de ser mantido em marombas (currais elevados) ou transportado para áreas de terra firme circunvizinhas.

Tabela 1. Dados Populacionais das comunidades de Caxiuanã e Pedreira (FLONA Caxiuanã, 1996) e São Benedito e Aracampina (llha de Ituqui, 1997), no Estado do Pará.

\begin{tabular}{lcccccc}
\hline & \multicolumn{2}{c}{ FLONA Caxiuanã } & & \multicolumn{2}{c}{ Ituqui } \\
\cline { 2 - 3 } \cline { 5 - 6 } & \multicolumn{2}{c}{ Caxiuanã Pedreira } & & São & Benedito & Aracampina \\
\hline Habitantes & 150 & 55,0 & & 240,0 & 380,0 \\
$\begin{array}{l}\text { Unidades } \\
\text { domésticas }\end{array}$ & 15 & 8,0 & & 36,0 & 60,0 \\
$\begin{array}{l}\text { Habitantes/unida- } \\
\text { des domésticas }\end{array}$ & 10 & 6,9 & & 6,7 & 6,3 \\
\hline
\end{tabular}

\section{Floresta Nacional de Caxiuanã}

A Floresta Nacional (FLONA) de Caxiuanã está situada nos municípios de M elgaço e Portel, ao sul da ilha de Marajó, no Estado do Pará. As comunidades estudadas, Pedreira e Caxiuanã, estão localizadas na área de influência da Floresta Nacional (FLONA) de Caxiuanã26. Pedreira situase no norte da baía de Caxiuanã, no entorno da FLONA, enquanto a comunidade de Caxiuanã está localizada dentro da área legal da última, às margens do Rio Curuáa ${ }^{6}$, na zona controlada pela Estação Científica Ferreira Penna (ECFPn), do M useu Paraense Emílio Goeldi (MPGE). Esta zona abarca $10 \%$ da área da FLONA de Caxiuanã (330 mil hectares).

O clima da região é caracterizado por dois perío dos de precipitação pluviométrica distintos, um mais chuvoso, de janeiro a maio, e outro menos chuvoso, nos demais meses do ano ${ }^{27}$. Dos ecossistemas que compõem a paisagem da região, predomina a floresta de terra firme, embora ocorram também porções de floresta permanentemente inundada (igapó), floresta de inundação periódica (sujeita aos regimes de cheia) e capoeiras (florestas secundárias em diferentes estágios de sucessão) $)^{28}$.

Os principais rios e igarapés da região apresentam água com coloração escura, e são, por isso, classificados como rios de águas pretas ${ }^{29}$. Embora os rios de águas pretas sejam conhecidos na região pela baixa produtividade primária e conseqüente escassez de alimentos (caça e pesca) em sua bacia ${ }^{30}$, as características edáficas da região de Caxiuanã e a influência do ecossistema de água branca do estuário amazônico devem suavizar um pouco este perfil oligotrófico.

De acordo com o último censo realizado na região, havia 206 habitantes vivendo na FLONA de Caxiuanã, distribuídos em 28 unidades domésticas $^{13}$. Em 1996 a comunidade de Caxiuanã era formada por 70 moradores, distribuídos em 11 unidades domésticas dispersas ao longo das margens do Rio Curuá, no entanto, estima-se que, atualmente, estes números tenham aumentado 
consideravelmente (15 unidades domésticas com aproximadamente 150 moradores) (Tabela 1$)^{13}$. Estes moradores são remanescentes de, aproximadamente, 350 famílias que viviam na região antes da criação da FLONA, em 1961. A comunidade de Pedreira não sofreu um êxodo como a de Caxiuanã durante a formação da FLONA, sendo basicamente a mesma desde sua formação no início da década de 70. É composta de 55 pessoas distribuídas em 8 unidades domésticas dispostas às margens da Baía de Caxiuanã.

De modo geral, as atividades econômicas desenvolvidas pelas populações são voltadas para a subsistência, sendo as mais comuns a agricultura, a caça, a pesca e a coleta de frutos. Há ainda importantes atividades extrativas, focadas principalmente na exploração da castanha-do-Pará (Bertholletia excelsa), do açaí (Euterpe oleracea), do óleo da copaíba (Copaifera multijuga) e de diversos tipos de madeiras ${ }^{31}$. Dentre os produtos cultivados, a mandioca (Manihot esculenta) configura-se como o produto mais importante para a maioria dos moradores. Alguns moradores de Caxiuanã são empregados pela ECFPn.

As unidades básicas de análise neste estudo são a unidade doméstica e o ecossistema. Para a avaliação e a quantificação do consumo alimentar foram conduzidos levantamentos em um total de 17 unidades domésticas na FLONA Caxiuanã, sendo 11 delas na comunidade de Caxiuanã e 6 na comunidade de Pedreira, representando, aproximadamente, $74 \%$ do total de unidades domésticas existentes. Em Ituqui, levantamento similar foi realizado em um total de 12 unidades domésticas, sendo 8 na comunidade de Aracampina e 4 em São Benedito, representando, aproximadamente, $12 \%$ do total de unidades domésticas. As unidades domésticas foram selecionadas com base em sua representatividade em termos de composição por sexo e idade, status socioeconômico e disposição em participar do trabalho ${ }^{12}$. A diferença entre as amostras de Ituqui e Caxiunã está relacionada à dimensão das comunidades da primeira e ao tamanho reduzido da equipe. Entretanto, acredita- se que as unidades domésticas estudadas em Ituqui são representativas do perfil socioeconômico da llha.

A metodologia utilizada foi o recordatório de 24 horas (24-hour food recall). Esse método consiste em entrevistas estruturadas, realizadas diariamente com os indivíduos, na maioria dos casos mulheres, responsáveis pela preparação de alimentos na unidade doméstica. Durante as entrevistas são coletadas informações acerca do tipo, processo de preparação, quantidade e origem dos alimentos consumidos nas últimas 24 horas $^{32,33}$. Os alimentos tiveram suas medidas obtidas com o auxílio de frascos graduados (Nalgon Equipamentos Científicos) de três dimensões, $100 \mathrm{~mL}, 500 \mathrm{~mL}$ e $2000 \mathrm{~mL}$, e balanças de precisão (Dinamômetros Crown, Oswaldo Filizola Ltda) com capacidade máxima de $500 \mathrm{~g}$ (precisão de $10 \mathrm{~g}$ ) e $3000 \mathrm{~g}$ (precisão de $50 \mathrm{~g}$ ). Dois tipos de balanças, com distintas capacidades máximas, foram utilizados para uma medição mais precisa dos diversos tipos e quantidades de alimentos consumidos. Além disso, os informantes eram instruídos, no início da pesquisa, a guardar os restos (ossos de animais e espinhas de peixes) para que, no dia seguinte, esses valores fossem subtraídos do cálculo de alimentos ingeridos.

$\mathrm{Na}$ tentativa de retratar as oscilações diárias e semanais, bem como sazonais, na disponibilidade e produção dos alimentos, o levantamento se estendeu por 7 dias consecutivos durante as estações chuvosa (inverno) e seca (verão). Os dados de consumo alimentar na llha de Ituqui foram obtidos em Outubro de 1995 (estação seca), e em Abril de 1996 (estação chuvosa). Já a coleta em Caxiuanã se deu em Julho de 2004 (estação seca) e em Fevereiro de 2005 (estação chuvosa).

Uma das limitações do método utilizado é a dificuldade de registro e pesagem dos alimentos consumidos pelos moradores fora de casa (refeições na casa de parentes, frutas colhidas e consumidas a caminho da roça etc.). Nem sempre foi possível obter informações precisas, principalmente no que se refere ao consumo das crianças ${ }^{9}$. Por fim, o método utilizado se apóia na memória e boa vontade dos participantes, que 
muitas vezes omitem ou esquecem as informações, o que pode gerar uma subnotificação ${ }^{34}$.

As medidas obtidas em campo, referentes ao consumo alimentar, foram convertidas em valores de energia (kcal) e proteína ( $\mathrm{g}$ ) usando uma compilação de várias tabelas de composição química de alimentos. A tabela elaborada pelo Instituto Nacional de Pesquisas do Amazonas (INPA $)^{35}$ foi usada preferencialmente, juntamente com a tabela recentemente desenvolvida pela Universidade Estadual de Campinas (Unicamp) ${ }^{36}$. Quando algum alimento não constava nessas tabelas, foram consultadas aquelas desenvolvidas pela Universidade de São Paulo (USP) ${ }^{37}$, pelo Instituto Brasileiro de Geografia e Estatística (IBGE) ${ }^{38}$ e por Franco ${ }^{39}$, nessa ordem. 0 uso de várias tabelas, privilegiando aquelas voltadas para alimentos brasileiros e amazônicos, foi a forma encontrada para minimizar potenciais erros provenientes da ausência da análise específica dos alimentos locais ${ }^{40}$

Para a conversão das medidas coletadas no campo em valores de energia (kcal) e proteína (g), foi utilizado o programa Statistical Package for Social Sciences versão $12.0^{41}$, também empregado nas análises estatísticas descritivas e inferenciais dos resultados. 0 teste estatístico utilizado foi a Análise de Variância (ANOVA).

Para a análise comparativa da contribuição energético-protéica por item alimentar e procedência foram considerados apenas os alimentos que contribuíram com, pelo menos, $4 \%$ do consumo de energia ou de proteínas nas unidades domésticas das populações estudadas. As formas de obtenção (procedência) dos alimentos foram assim categorizadas: agricultura, caça, coleta, compra, extração, pesca, presenteio, pecuária e outros.

A anuência para realização da pesquisa foi obtida oralmente, seguindo o procedimento das instituições de pesquisa estabelecido nas áreas de estudo. Entretanto todos os princípios éticos contidos na Declaração de Helsinki $\mathrm{VI}^{42}$ foram atendidos.
RESULTA DOS

\section{Contribuição energético-protéica}

A dieta em Ituqui é estruturada, predominantemente, sobre o consumo de peixe e farinha de mandioca. A mandioca representou $30,2 \%$ do total energético consumido nas unidades domésticas de Ituqui, considerando-se ambas as estações (seca e chuvosa) nas duas comunidades estudadas, Aracampina e São Benedito (Tabela 2). 0 peixe, por sua vez, além de sua importância como fonte protéica, representou a segunda fonte mais proeminente de energia em Ituqui, fornecendo $22,9 \%$ da energia consumida nas unidades domésticas. Em seguida, representando $10,7 \%$ da energia consumida, está o açúcar. Os cereais (trigo, aveia e derivados) representaram $6,5 \%$ do consumo energético, constituindo uma fonte não animal importante para o cômputo energético geral em Ituqui. A segunda fonte energética animal mais relevante foi o leite, com $4,9 \%$ do total energético consumido.

Tabela 2. Contribuição energética e protéica dos itens alimentares presentes na dieta das comunidades situadas na FLONA Caxiuanã (2004-2005) e em Ituqui (1995-1996) (estação seca e chuvosa combinadas), no Estado do Pará.

\begin{tabular}{|c|c|c|c|c|c|c|}
\hline \multirow[b]{2}{*}{ Alimento } & \multicolumn{3}{|c|}{ Energia (\%) } & \multicolumn{3}{|c|}{ Proteínas (\%) } \\
\hline & Ituqui & $\begin{array}{c}\text { FLONA } \\
\text { Caxiuanã }\end{array}$ & $p$ & Ituqui & $\begin{array}{c}\text { FLONA } \\
\text { Caxiuanã }\end{array}$ & $p$ \\
\hline Açaí & 0,0 & 17,0 & $<0,0001$ & 0,0 & 9,4 & $<0,0001$ \\
\hline Açúcar & 10,7 & 6,3 & $<0,0001$ & 0,0 & 0,0 & $\ldots$ \\
\hline $\begin{array}{l}\text { Carne } \\
\text { bovina }\end{array}$ & 0,0 & 0,0 & $\ldots$ & 2,6 & 6,4 & 0,256 \\
\hline $\begin{array}{l}\text { Carnes de } \\
\text { caça }\end{array}$ & 0,0 & 0,0 & $\cdots$ & 1,2 & 6,8 & 0,005 \\
\hline Cereais & 6,5 & 3,5 & 0,130 & 4,3 & 2,8 & 0,069 \\
\hline Peixe & 22,9 & 13,9 & 0,001 & 61,6 & 54,3 & 0,564 \\
\hline Frango & 0,0 & 0,0 & $\ldots$ & 6,3 & 1,5 & 0,129 \\
\hline Leite & 4,9 & 0,6 & $<0,0001$ & 6,7 & 1,2 & $<0,0001$ \\
\hline Mandioca & 30,2 & 43,7 & $<0,0001$ & 4,6 & 10,3 & $<0,0001$ \\
\hline Outros & 24,8 & 15,0 & $\ldots$ & 12,7 & 7,3 & $\ldots$ \\
\hline Total & 100,0 & 100,0 & $\ldots$ & 100,0 & 100,0 & $\ldots$ \\
\hline
\end{tabular}

$\mathrm{Na}$ categoria outros, encontram-se todos os demais itens alimentares tais como ovos, feijão, óleo, margarina, demais frutas, verduras etc 
A farinha de mandioca e o peixe também foram os itens alimentares de maior importância na dieta das comunidades da FLONA Caxiuanã (Tabela 2). Como em Ituqui, a mandioca representa a maior fonte de energia em Caxiuanã, totalizando $43,7 \%$. Contudo, nessas comunidades há outro item alimentar de grande importância, 0 açaí, que provê $17,0 \%$ da energia consumida. Também aqui, o peixe aparece como a fonte animal de energia mais importante, fornecendo $13,9 \%$ do total consumido. E, finalmente, o açúcar, que representa $6,3 \%$ da energia consumida nas unidades domésticas de Caxiuanã.

Ao comparar os valores de contribuição energética (Tabela 2 ) dos itens alimentares presentes nas dietas das unidades domésticas na FLONA Caxiuanã com os de Ituqui (estação seca e chuvosa combinadas), foram observadas diferenças estatisticamente significantes nos seguintes itens: mandioca $(p<0,0001)$, leite $(p<0,0001)$, peixe $(p=0,001)$ e açúcar $(p<0,0001)$.

0 peixe é a fonte dominante de proteínas em Ituqui (Tabela 2), representando $61,6 \%$ do total consumido na unidades domésticas. Em seguida apareceram o leite e o frango, fornecendo $6,7 \%$ e $6,8 \%$ das proteínas consumidas, respectivamente. A mandioca é a fonte de proteínas não animal mais importante na dieta de Ituqui, fornecendo $4,6 \%$ das proteínas ingeridas. Os cereais vieram logo a seguir, com 4,3\% .

0 peixe também é a principal fonte de proteínas entre as unidades domésticas de Caxiuanã (Tabela 2), representando 54,3\% do total consumido. Outros itens alimentares de origem animal, como as carnes de caça e bovina, são importantes fontes protéicas, contribuindo com $6,8 \%$ e $6,4 \%$ do consumo das unidades domésticas, respectivamente. A mandioca também tem grande contribuição protéica, sendo a principal fonte não-animal de proteína para a dieta de Caxiuanã, contabilizando $10,3 \%$ das proteínas ingeridas. 0 açaí, além de sua relevância como fonte energética, aparece como a terceira mais importante fonte protéica, e a segunda fonte não animal, fornecendo 9,4\% das proteínas consumidas na FLONA Caxiuanã.
A penas os valores referentes à contribuição protéica do leite $(p<0,0001)$, da mandioca $(p<0,0001)$ e da carne de caça $(p=0,005)$ apresentaram diferenças significantes entre as unidades domésticas de Ituqui e a da FLONA Caxiuanã (Tabela 2). Itens alimentares que não foram observados em um dos ecossistemas, como é o caso do açaí, mesmo que tenham atingido $4 \%$ do consumo energético ou protéico, não receberam tratamento estatístico inferencial, já que a diferença é claramente identificada.

\section{Sazonalidade de itens alimentares}

Em Ituqui, foi observado o aumento significante da contribuição energética do açúcar $(p=0,039)$ no inverno em relação ao verão. 0 mesmo ocorreu com a contribuição energética do frango $(p=0,007)$. Por outro lado, houve uma queda significante na contribuição do leite $(p=0,005)$ no inverno. No que se refere ao consumo protéico, houve aumento significante da contribuição do frango $(p=0,002)$ e queda da do leite $(p=0,005)$ no inverno.

Na FLONA Caxiuanã foi também observada uma contribuição energética significantemente maior do açúcar $(p=0,042)$ no inverno. Já no caso do açaí, foram observados valores menores de contribuição energética no inverno $(p=0,006)$. No que se refere ao consumo protéico, 0 açaí $(p=0,004)$ foi o único item alimentar que teve uma variação sazonal significativa, apresentando os menores valores no inverno.

\section{Procedência de energia e proteínas}

Na FLONA Caxiuanã, observa-se uma grande dependência da agricultura, origem de 35,9\% da energia consumida nas unidades domésticas (Tabela 3). Os itens obtid os por compra também têm um papel importante, uma vez que contribuem com $19 \%$ da energia. Em seguida, estão a extração, majoritariamente de açaí, a pesca e o presenteio entre as unidades domésticas, contribuindo com $13,2 \%, 11,3 \%$ e $10,9 \%$ da energia ingerida, respectivamente. 
Tabela 3. Porcentagem de contribuição energética e protéica por procedência, na FLONA Caxiuanã (2004-2005) e em Ituqui (1995-1996) (estação seca e chuvosa combinadas), no Estado do Pará.

\begin{tabular}{|c|c|c|c|c|c|c|}
\hline \multirow[b]{2}{*}{ Categoria } & \multicolumn{3}{|c|}{ Energia (\%) } & \multicolumn{3}{|c|}{ Proteínas (\%) } \\
\hline & Ituqui & $\begin{array}{c}\text { FLONA } \\
\text { Caxiuanã }\end{array}$ & $p$ & Ituqui & $\begin{array}{c}\text { FLONA } \\
\text { Caxiuanã }\end{array}$ & p \\
\hline Compra & 49,2 & 19,0 & $<0,0001$ & 20,6 & 9,5 & 0,085 \\
\hline Extração & 0,0 & 13,2 & $<0,0001$ & 0,0 & 5,3 & $<0,0001$ \\
\hline Agricultura & 7,8 & 35,9 & $<0,0001$ & 0,7 & 6,3 & 0,001 \\
\hline Pesca & 20,8 & 11,3 & 0,040 & 56,1 & 48,2 & 0,136 \\
\hline Presentes & 4,9 & 10,9 & 0,040 & 4,7 & 17,9 & 0,020 \\
\hline Caça & 0,1 & 1,7 & 0,183 & 0,4 & 6,3 & 0,305 \\
\hline Coleta & 0,0 & 4,0 & $<0,0001$ & 0,0 & 2,0 & $<0,0001$ \\
\hline Pecuária & 3,4 & 0,0 & $<0,000$ & 7,9 & 0,0 & $<0,0001$ \\
\hline Outros & 13,8 & 4,0 & $\ldots$ & 9,6 & 4,5 & $\ldots$ \\
\hline Total & 100,0 & 100,0 & $\cdots$ & 100,0 & 100,0 & $\ldots$ \\
\hline
\end{tabular}

Em Ituqui, foi observada uma maior dependência em relação aos itens comprados, fonte de $49,2 \%$ da energia consumida (Tabela 3). A pesca também aparece como atividade importante, contribuindo com 20,8\% da ingestão energética. Contudo, ao contrário da FLONA Caxiuanã, a agricultura contribui bem menos para a dieta local (7,8\% da ingestão energética).

Diferenças estatisticamente significantes entre os dois ecossistemas, no que diz respeito à contribuição energética, foram observadas em praticamente todas as procedências que ocorreram em ambas as populações: compra $(p<0,0001)$, agricultura $(p<0,0001)$, pesca $(p=0,040)$ e presentes $(p=0,040)$. A categoria pecuária não foi observada em Caxiuanã, enquanto extração e coleta não foram observadas em Ituqui.

No que se refere às proteínas, a pesca mostrou ser a mais importante fonte protéica para as dietas das unidades domésticas de Caxiuanã, contribuindo com $48,2 \%$ do total consumido (Tabela 3). Em seguida, o presenteio aparece como a segunda fonte protéica de maior importância, com 17,9\% do consumo total. Já os itens obtidos por compra contribuem com $9,5 \%$ das proteínas consumidas nas unidades domésticas.

Em Ituqui, a importância da pesca como fonte protéica é ainda maior, contribuindo com $56,1 \%$ do consumo total das unidades domésticas.
A compra, além da sua relevância no consumo energético, também mostra valores elevados de contribuição protéica em Ituqui, provendo 20,6\% das proteínas consumidas. A pecuária e 0 presenteio vêm em seguida, representando 7,9\% e $4,7 \%$ das proteínas consumidas pelas unidades domésticas de Ituqui, respectivamente.

Diferenças estatisticamente significantes entre os dois ecossistemas foram constatadas para as proteínas procedentes $d a$ agricultura $(p=0,001)$ e do presenteio $(p=0,020)$.

\section{I S C U S S Ã O}

O consumo alimentar em ambos os ecossistemas é dominado pelo pescado e pela mandioca e seus derivados. A importância da mandioca é maior em Caxiuanã, provavelmente devido aos problemas que o cultivo desta planta enfrenta na várzea de Ituqui. M esmo considerando o fato de os moradores de Ituqui procurarem manter uma atividade produtiva neste período em áreas na Terra Firme ${ }^{23}$, livres do estresse anual da cheia, é difícil contornar as perdas anuais para as inundações. 0 elevado consumo de açúcar no inverno em Ituqui talvez esteja relacionado à tentativa de estabilizar a ingestão energética em função das dificuldades enfrentadas no cultivo da mandioca, principalmente no período de maior escassez de alimentos ${ }^{1,12}$.

0 peixe, por sua vez, mostra maior contribuição energética nas comunidades de Ituqui, o que é explicado pela maior produtividade do Rio Amazonas, em comparação aos rios de água preta da FLONA Caxiuanã. Contudo, como já foi observada, a diferença na contribuição energética não é acompanhada por uma diferença proporcional na contribuição protéica, o que parece indicar que há uma variação nas espécies de peixes consumidos. Pode ser que, em Ituqui, haja um maior consumo de espécies de peixes com elevados teores de gordura e maior porte. Entretanto, esta hipótese não pode ser testada com os dados disponíveis no momento.

No que tange à diferença na contribuição protéica da mandioca entre Ituqui e Caxiuanã, 
foi observado o mesmo padrão relacionado à ingestão energética. 0 leite tem menor contribuição para as comunidades da FLONA Caxiuanã, pois lá não há criação de gado, sendo o leite consumido na forma enlatada em pó e obtido, por meio de compra nas cidades de M elgaço e Portel.

Em termos de variação sazonal, foi observado o aumento da contribuição energética do açúcar e do frango em Ituqui no inverno, provavelmente devido às dificuldades de obtenção de alimentos nesta estação. Considerando que 0 frango é, na maioria dos casos, originário da própria criação doméstica, seu consumo mais freqüente sugere que esta seja uma estratégia de caráter mais emergencial. Por outro lado, houve uma queda significativa na contribuição energética do leite no inverno, muito provavelmente causada pelas condições de vida estressantes do gado nessa estação, que é mantido em marombas (currais elevados). Neste período, o trabalho dos homens é redobrado, já que todos os dias eles precisam sair à procura de capim flutuante nas margens de rios e lagos para a alimentação dos animais. Contudo, esse esforço não impede o enfraquecimento do gado, causando a interrupção completa da produção de leite ${ }^{10-12}$. A companhando os valores de energia, houve aumento da contribuição protéica do frango e queda na contribuição protéica do leite no inverno.

Na FLONA Caxiuanã, a redução da contribuição energético-protéica do açaí está relacionada diretamente à queda da produção dos açaizais no inverno. Essa queda é compensada pelo aumento da ingestão de açúcar e outros itens, como a bacaba e a castanha-do-Pará, amenizando, assim, as dificuldades do inverno.

Ituqui revelou uma maior dependência em relação aos itens comprados para o seu consumo energético, enquanto as unidades domésticas da FLONA Caxiuanã mostraram estar ainda bastante vinculadas à agricultura. A diferença em relação à extração pode ser explicada pela ausência de bosques de açaí nas comunidades de Ituqui. Além do açaí, a coleta de castanha-do-Pará e de outras frutas silvestres também contribui para a categoria coleta na FLONA Caxiuanã, uma vez que não há ocorrência dessas espécies em Ituqui. Já a discrepância no tocante à categoria pesca parece estar ligada à mesma causa comentada acima para o papel do peixe na ingestão energética - maior produtividade do Rio Amazonas e seus lagos interiores.

Da mesma forma, as explicações dadas acima para as diferenças encontradas na contribuição energética da agricultura, da extração e da coleta, podem ser aplicadas às proteínas. Ainda, na FLONA Caxiuanã, o presenteio e a caça tiveram maior contribuição protéica. No caso do primeiro, os valores obtidos parecem refletir a maior importância simbólica e econômica das redes de troca e solidariedade em Caxiuanã, bem como uma maior ênfase nas trocas monetárias em Ituqui. Já no que diz respeito à caça, o acesso fácil a áreas de terra firme de uma floresta relativamente protegida pode explicar a importância desta categoria na FLONA Caxiuanã.

\section{O N CLUSÃ O}

A análise e a comparação dos dados de consumo alimentar das populações ribeirinhas da FLONA Caxiuanã e da llha de Ituqui vão ao encontro de trabalhos anteriores, que indicam uma grande dependência das comunidades ribeirinhas no clássico binômio culinário amazônico: pescado e mandioca ${ }^{12,15}$. Ademais, o peixe, além de ser a maior fonte de proteínas, é também a mais importante fonte animal de energia ${ }^{12,14}$.

Além disso, foi observada, nas unidades domésticas em ambos os ecossistemas estudados, uma variação sazonal de itens alimentares secundários, como o açúcar, o leite, o frango e o açaí. Este último, apesar de apresentar valores mais baixos em termos de contribuição energética, parece servir para estabilizar a ingestão energética e protéica na FLONA Caxiuanã ao longo do ano. Com relação às procedências da energia e das proteínas consumidas, Ituqui revelou uma maior dependência de itens alimentares comprados, enquanto Caxiuanã mostrou estar ainda bastante vinculada à agricultura. Parece também haver diferenças no tocante à pesca, provavelmente ligada à maior produtividade dos rios e lagos da 
várzea, à variedade e ao porte dos peixes consumidos nos diferentes ecossistemas. Em relação ao presenteio, os valores obtidos parecem refletir a maior importância social e econômica das redes de troca e solidariedade em Caxiuanã.

Finalmente, produtos industrializados, como o açúcar, revelarem ter um papel importante nas dietas locais, e podem apontar para tendências no consumo alimentar relacionadas com a atual, e ainda pouco compreendida, transição nutricional, bem como com a erosão dos sistemas de subsistência locais ${ }^{12}$. No caso específico da FLONA Caxiuanã, esta tendência pode estar ligada às restrições da legislação ambiental, que regula as práticas agrícolas e extrativas dentro da FLONA e nas áreas vizinhas. Enquanto que em Ituqui, este processo pode estar relacionado às limitações impostas pela variação sazonal extrema do ecossistema de várzea, caracterizada pelas cheias periódicas. A impossibilidade de cultivo ao longo de todo 0 ano e a diminuição significativa do pescado durante o inverno são conseqüências diretas deste regime.

\section{A GRA DECIMENTOS}

Ao Museu Paraense Emílio Goeldi, à equipe da Estação Científica Ferreira Penna e aos moradores de Caxiuanã, Pedreira, São Benedito e Aracampina, pelo apoio e amizade.

\section{COLABORADORES}

R.S.S. MURRIETA e M.S. BAKRI são responsáveis pela coleta e análise dos dados, pela estrutura e pela redação do texto. C. ADAMS auxiliou na análise e na coleta de dados. P.S.S. OLIVEIRA e R. STRUMPF auxiliaram na coleta de dados.

\section{RE FERÊ N C I A S}

1. World Health Organization. Expert consultation: diet, nutrition and chronic diseases. Geneva: World Health Organization; 2003.

2. Bermudez $\mathrm{Ol}$, Tucker $\mathrm{KL}$. Trends in dietary patterns of Latina American populations. Cad Saúde Pública. 2003; 19(Suppl 1):587-99.
3. Godoy R, Reyes-García V, Byron E, Leonard WR, Vadez $V$. The effect of market economies on the well-being of indigenous people and on their use of renewable natural resources. Ann Rev Anthropol. 2005; 34:121-38.

4. Instituto Brasileiro de Geografia e Estatística. Pesquisa de orçamentos familiares 2002-2003. Antropometria e análise do estado nutricional de crianças e adolescentes no Brasil. Rio de Janeiro: IBGE; 2006.

5. Monteiro AC, Conde WL, Popkin BM. Trends in under and overnutrition in Brazil. In: Cabalero $B$, Popkin BM, editors. The nutrition transition: diet and disease in the developing world. New York: Academic Press; 2002.

6. Peña M, Bacallao J. Malnutrition and poverty. Ann Rev Nutr. 2002; 22:241-53.

7. Stinson SF. Nutritional adaptation. Ann Rev Anthropol. 1992; 21:143-70.

8. Dufour D. Nutritional ecology in the tropical rainforests of Amazonia. Am J Hum Biol. 1992; 4(2):108-207.

9. Murrieta RSS, Dufour D, Siqueira SA. Food consumption and subsistence in three caboclo populations on Marajo Island, Amazônia, Brazil. Hum Ecol. 1999; 27(3):455-75.

10. Murrieta RSS. O dilema do papa-chibé: consumo alimentar, nutrição e práticas de intervenção. Rev Antropol. 1998; 41(1):97-150.

11. M urrieta RSS. Dialética do sabor: alimentação, ecologia e vida cotidiana em comunidades ribeirinhas da llha de Ituqui, Baixo Amazonas, Pará. Rev Antropol. 2001; 44(2):39-88.

12. Murrieta RSS, Dufour D. Fish and flour: protein and energy consumption in Amazon rural communities on Ituqui Island, Brazil. Ecol Food Nutr. 2004; 43(3):231-55.

13. Silva HP. Aspectos demográficos e médicoepidemiológicos das comunidades de Caxiuanã, Melgaço, Pará. In: Lisboa PL, organizador. Caxiuanã: populações tradicionais, meio físico e diversidade biológica. Belém: Museu Paraense Emílio Goeldi; 2002.

14. Adams C. Estratégias adaptativas de duas populações caboclas (Pará) aos ecossistemas de Várzea estuarina e estacional: uma análise comparativa [tese]. São Paulo: Instituto de Biociências, Universidade de São Paulo; 2002.

15. Adams C, M urrieta RSS, Siqueira AD, Neves WA. 0 pão da terra: da invisibilidade da mandioca na Amazônia. In: Adams C, M urrieta RSS, Neves WA, organizadores. Sociedades caboclas amazônicas: modernidade e invisibilidade. São Paulo: Annablume; 2006. 
16. Nugent S. Amazonian caboclo society: an essay on invisibility and peasant economy. Oxford: Berg; 1993.

17. Moran EF, Brondízio ES. Land-use change after deforestation in Amazônia. In: Liverman EFMD, Rindfuss RR, Stern PC. People and pixels: linking remote sensing and social science. Washington (DC): National Academy Press; 1998.

18. Murrieta RSS. Diet and subsistence: changes in three caboclo populations on Marajó Island, Brazil [thesis]. Boulder: University of Colorado; 1994

19. Giugliano R, Shrimpton L, Arkol D, Giugliano LG, Petreri $M$. Diagnóstico da realidade alimentar e nutricional do Estado do Amazonas. Acta Amazônica. 1978; 8(2):5-53.

20. Silva AL, Begossi A. Uso de recursos por ribeirinhos no médio Rio Negro. In: Ecologia de pescadores da Mata Atlântica e da Amazônia. São Paulo: Hucitec; 2004.

21. Giugliano R, Shrimpton R, Marinho HA, Giugliano LG. Estudos nutricionais das populações rurais da Amazônia. Il- Rio Negro. Acta. 1984; 14(3-4): 427-49.

22. Piperata BA. The energetics of lactation among tropical horticulturists in the Brazilian Amazon [thesis]. Boulder: University of Colorado; 2005.

23. Winklerprins AM. Between the Floods: soils and agriculture on the Lower Amazon Floodplain, Brazil [thesis]. Madison: University of Wisconsin; 1999.

24. Câmara EPL, M cGrath DG. A Viabilidade da Reserva de Lago como unidade de manejo sustentável dos recursos da várzea Amazônica. Bol Museu Paraense Emílio Goeldi. Série Antropologia. 1995; 11(1): 87-132.

25. M cGrath DG, Silva UL, Crossa NM M. A Traditional Floodplain Fishery of the Lower Amazon River, Brazil. ICLARM Quarterly. 1998; Jan-Mar: 4-11.

26. Ramos KN. Análise de fluxos materiais em três comunidades impactadas pela instituição da Floresta Nacional de Caxiuanã-PA [dissertação]. Belém: Universidade Federal do Pará; 2001.

27. Oliveira MC, Costa AC, Costa JP, Palheta M C, Pereira MG. Comportamento dos elementos metereológicos. In: Lisboa PL, organizador. Caxiuanã: populações tradicionais, meio físico e diversidade biológica. Belém: Museu Paraense Emílio Goeldi; 2002.

28. Lisboa PLB. A estação científica Ferreira Penna/ ECFPn-(1993-2002) In: Lisboa PLB, organizador. Caxiuanã: populações tradicionais, meio físico e diversidade biológica. Belém: Museu Paraense Emílio Goeldi; 2002.

29. Sioli H. The Amazon: limnology and landscape ecology. Dordrecht: Junk Publishers; 1984.
30. M oran EF. A ecologia humana das populações da Amazônia. Rio de Janeiro: Vozes; 1990.

31. Silveira IM, Quaresma HDB, Guapindai VL, $M$ achado AL. As populações pré-históricas e atuais. In: Lisboa PLB, organizador. Belém: M useu Paraense Emílio Goeldi; 1997.

32. Brown KN. Measurement of dietary intake. In: Mosley WH, Chen LC, editors. Population and development review. New York: The Population Council; 1984.

33. Dufour D, Teufel NI. Minimum data sets for the description of diet and measurement of food intake and nutritional status. In: Moran EF, editor. The study of agrarian systems: standardizing measurements and minimun data sets. Boulder: Lynne Reiner Publishers; 1995.

34. Scagliusi FB, Lancha Júnior AH. Subnotificação da ingestão energética na avaliação do consumo alimentar. Rev Nutr. 2003; 16(4):471-81.

35. Instituto Nacional de Pesquisa do Amazonas. Composição de alimentos da Amazônia. Manaus: Coordenação de Pesquisas em Ciências da Saúde; 1998.

36. Universidade Estadual de Campinas. Tabela brasileira de composição de alimentos. Campinas: Unicamp; 2004.

37. Philippi ST. Tabela de composição de alimentos: suporte para decisão nutricional. São Paulo: Universidade de São Paulo; 2002.

38. Instituto Brasileiro de Geografia e Estatística. Estudo nacional de despesa familiar: tabela de composição de alimentos. Rio de Janeiro: IBGE; 1999.

39. Franco G. Tabela de composição química dos alimentos. Rio de Janeiro: Atheneu; 1996.

40. Rocha YR, Aguiar JPL, Marinho HA, Shrimpton R. Aspectos nutritivos de alguns peixes da Amazônia. Acta Amazônica. 1982; 12(4):787-94.

41. Statistical Package for Social Sciences 12.0.1 for Windows. Statistics program. Chicago (IL): SPSS Inc; 2003.

42. Associação Médica Mundial. Declaração de Helsinki VI. Adotada na 18a. Assembléia Médica Mundial, Helsinki, Finlândia (1964), alterada na 29a. Assembléia, em Tóquio, Japão (1975), 35a. em Veneza, Itália (1983), 41a. em Hong Kong (1989), 48a. Sommerset West/África do Sul (1996) e 52a. Edimburgo/Escócia (out/2000).

Recebido em: 1/3/2007

Versão final reapresentada em: 14/11/2007

Aprovado em: 8/5/2008 
